\title{
Moraxella (Branhamella) catarrhalis - clinical and molecular aspects of a rediscovered pathogen
}

\author{
M. C. ENRIGHT and H. MCKENZIE*
}

Microbial Genetics Group, Department of Biological Sciences, University of Sussex, Falmer, Brighton BN1 $9 Q G$ and ${ }^{*}$ Department of Medical Microbiology, University of Aberdeen Medical School, Foresterhill, Aberdeen $A B 252 Z D$

\begin{abstract}
Since its discovery at the end of the nineteenth century, Moraxella (Branhamella) catarhalis has undergone several changes of nomenclature and periodic changes in its perceived status as either a commensal or a pathogen. Molecular analysis based on DNA hybridisation or 16S rDNA sequence comparisons has established its phylogenetic position as a member of the Moraxellaceae and shown that it is related more closely to Acinetobacter spp. than to the genus Neisseria in which it was placed formerly. However, confusion with phenotypically similar Neisseria spp. can occur in the routine diagnostic laboratory if appropriate identification tests are not performed. $M$. catarrhalis is now accepted as the third commonest pathogen of the respiratory tract after Streptococcus pneumoniae and Haemophilus influenzae. It is a significant cause of otitis media and sinusitis in children and of lower respiratory tract infections in adults, especially those with underlying chest disease. Nosocomial spread of infection, especially within respiratory wards, has been reported. Invasive infection is uncommon, but analysis of reports for England and Wales between 1992 and 1995 revealed 89 cases of $M$. catarrhalis bacteraemia, with the peak incidence in children aged 1-2 years. Carriage rates of $M$. catarrhalis are high in children and in the elderly, but its role as a commensal organism has probably been overstated in the past. Approximately $90 \%$ of strains are now $\beta$ lactamase positive and, given that the first such strain was reported in 1976, this represents a dramatic increase in frequency over the last 20 years which has not been paralleled in any other species. The BRO-1 and BRO-2 $\beta$-lactamase enzymes of $M$. catarrhalis are found in other Moraxellaceae, but are not related to $\beta$-lactamases of any other species and their origin is therefore unknown. Molecular and typing studies have shown that the $M$. catarrhalis species is genetically heterogeneous and these methods have aided epidemiological investigation. Studies of factors that may be related to pathogenicity have shown the existence of three serotypes of lipooligosaccharide and the presence of fimbriae and a possible capsule. Some strains are serum-resistant, probably by virtue of interference with complement action, whilst transferrin- and lactoferrinbinding proteins enable the organism to obtain iron from its environment. An antibody response in humans to various $M$. catarrhalis antigens, including highly conserved outermembrane proteins, has been demonstrated. Increased understanding of the organism's pathogenic properties and the host response to it may help to identify suitable vaccine targets or lead to other strategies to prevent infection. Whilst it remains, at present, the third most important respiratory pathogen, the impact of immunisation strategies for other organisms may change this position. The speed with which $M$. catarrhalis acquired $\beta$-lactamase demonstrates the capacity of this organism to surprise us.
\end{abstract}

\section{Introduction}

Moraxella catarrhalis is an aerobic, oxidase-positive, gram-negative diplococcus which is now generally

Received 2 Sept. 1996; accepted 22 Oct. 1996.

Corresponding author: Dr H. McKenzie. accepted as a pathogen, although until relatively recently it was considered to be a harmless commensal of the upper respiratory tract. It is morphologically and phenotypically similar to Neisseria spp. and, in the past, this has resulted in the misidentification of $M$. catarrhalis as a species of the latter genus, most notably as $N$. cinerea, a commensal organism of the 
adult pharynx. $M$. catarrhalis is now recognised as an important cause of respiratory tract infections in the elderly and in those with pre-existing respiratory disease, as a common cause of otitis media in children, and as an occasional cause of invasive disease.

Previous reviews [1, 2] documented that the organism was named Mikrokokkus catarrhalis by Pfeiffer [3] in 1896, although it had probably been discovered 14 years earlier in 1882 by Seifert [4]. In his fascinating review of the history of $M$. catarrhalis, Berk [2] described the evidence of Ghon and Pfeiffer [5] that this organism, along with Streptococcus pneumoniae and the organism now known as Haemophilus influenzae, is a respiratory pathogen. Early this century in 1905, Dunn and Gordon [6] investigated an apparent influenza epidemic in East Hertfordshire and demonstrated three different kinds of gramnegative cocci in respiratory secretions on the basis of cultural characteristics and carbohydrate fermentation tests. $M$. catarrhalis was the commonest isolate and was considered to be a significant pathogen. However, a study on gram-negative cocci in the common cold and influenza by Gordon in 1921 [7] described $M$. catarrhalis as a saprophyte of negligible virulence found in the throat of healthy adults. This view, that $M$. catarrhalis is a harmless commensal, has persisted for much of the remainder of this century and it has only recently regained prominence as a pathogenic organism.

The nomenclature of $M$. catarrhalis has changed several times and its current designation in the 1984 edition of Bergey's Manual of Systematic Bacteriology as Moraxella (Branhamella) catarrhalis [8] is a compromise between two views. One suggests that M. catarrhalis is related so closely to other. Moraxella spp. that it should be included in this genus, regardless of the fact that it would be a coccoid organism in a genus of bacillus-shaped species, as would the closely related 'false Neisseria' organism now known as $M$. caviae. The alternative view held by Catlin [9] proposes the formation of a new family - Branhamaceae - to include two genera, Moraxella and Branhamella. Genetic studies with DNA-DNA [10] and rRNA-DNA hybridisation techniques [11] suggest that $M$. catarrhalis is sufficiently similar to other Moraxella spp. to satisfy the usual criteria for inclusion in the same genus. More recently, we have compared 16S rDNA sequences from selected species of Moraxella and related genera [12]. The dendrogram (Fig. 1) is based on comparisons of these sequences and demonstrates that $M$. catarrhalis is closely related to $M$. lacunata subsp. lacunata and to the 'false Neisseria' $N$. ovis. There is no evidence to support the case for a separate Branhamella genus, and $M$. catarrhalis is related more closely to Acinetobacter spp. than to Neisseria spp. On these genetic grounds the organism will be referred to throughout this review as $M$. catarrhalis.

The 1984 edition of Bergey's Manual of Systematic Bacteriology [8] describes $M$. catarrhalis colonies of c. $2 \mathrm{~mm}$ diameter after incubation for $48 \mathrm{~h}$ on agar. Colonies are opaque, non-haemolytic and, characteristically, can be pushed along the surface of the agar with a loop, like a hockey puck [13]. M. catarrhalis does not utilise sucrose, glucose, maltose and lactose

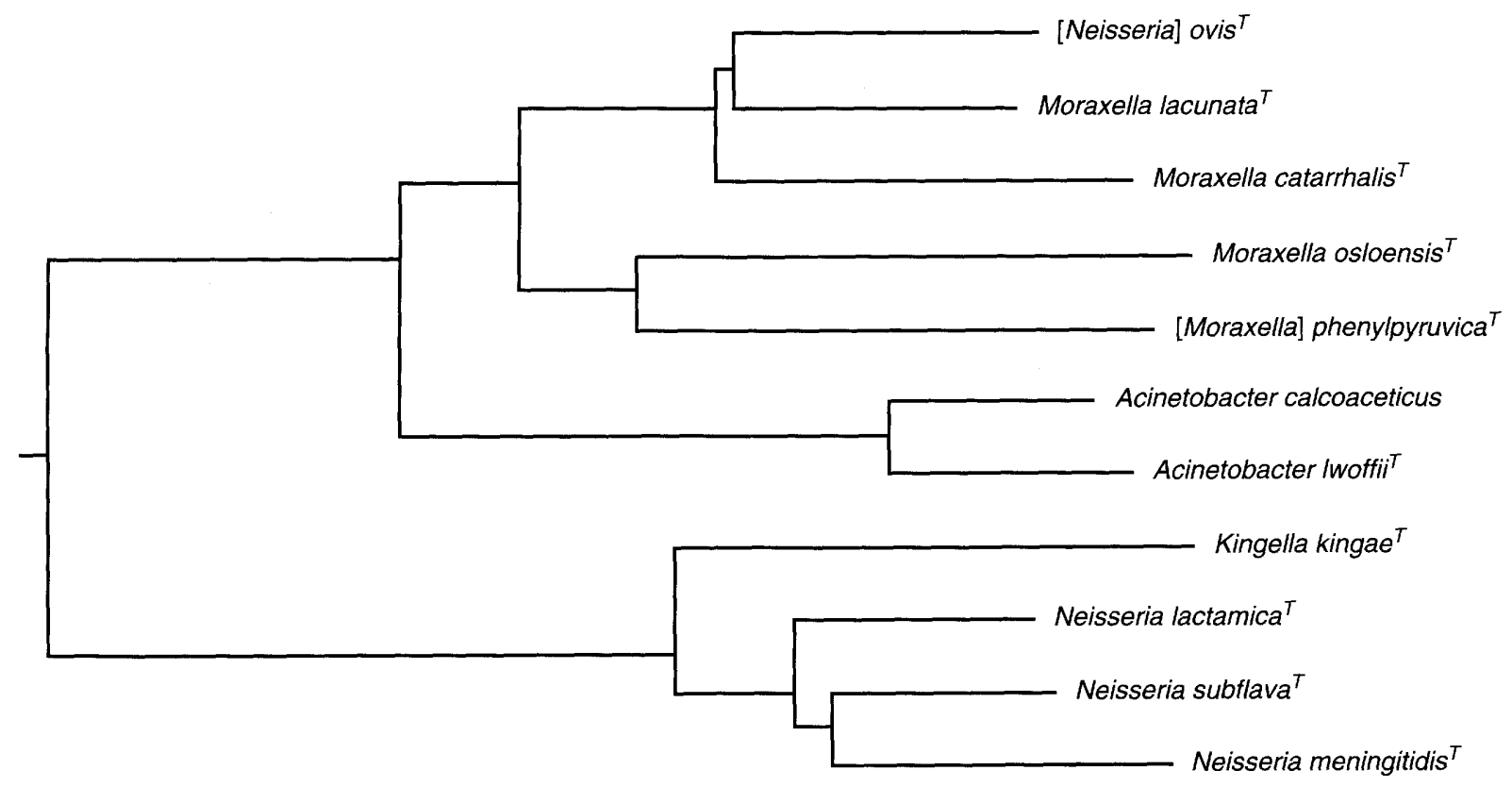

Fig. 1. Rooted phylogenetic tree representing the degree of similarity between 16S rDNA sequences in selected species of Moraxella and other related genera. Horizontal distances are equivalent to genetic distances; vertical distances have no meaning. Scale: - represents a genetic distance of $0.2 \%$. ${ }^{T}$ Type strain of species. (Reproduced from Enright et al. [12] with permission). 
- the sugars used commonly for the identification of Neisseria spp. - but reliance on these criteria alone can lead to misidentification, as certain commensal neisserias, such as $N$. cinerea, have a similar negative reaction pattern. $M$. catarrhalis reduces both nitrate and nitrite and produces DNAase. A report on the identification of $M$. catarrhalis in the diagnostic laboratory [14] found that the tests listed above, with the addition of the superoxol test [15], were sufficient to differentiate between $M$. catarrhalis and morphologically similar Neisseria spp. A further useful additional test for identification of $M$. catarrhalis in the routine laboratory detects the presence of tributyrin esterase, which is produced by all strains [16]. Moraxellaceae other than $M$. catarrhalis may also be positive in the tributyrin test; therefore, DNAase or nitrate reduction tests should be performed for definitive identification [17]. Thus there are several potential pitfalls in the identification of $M$. catarrhalis, and these complicate the interpretation of clinical and microbiological studies on this organism, especially older studies performed before these difficulties became apparent.

\section{Clinical significance}

The widely held view that $M$. catarrhalis is a common commensal of the nasopharynx is correct in children. A prospective study of 120 infants that examined nasopharyngeal carriage found that $66 \%$ of those tested were colonised with the organism at the age of 1 year, rising to $77.5 \%$ by the age of 2 years, with colonised infants showing a significantly greater risk of presenting with otitis media caused by $M$. catarrhalis [18]. Other studies have found carriage rates of $48.9 \%$ in children aged 3-12 years [19] and 54\% in children aged $<4$ years [20]. However, carriage rates are much lower in adults, with $1 \%$ carriage reported in 561 women admitted to hospital in labour [19] and 5.8\% carriage found in another study of healthy adults, although this rose to $26.5 \%$ in people aged $>60$ years [20]. The latter study critically examined 112 papers which stated that $M$. catarrhalis is a common commensal organism and found that none of these papers presented experimental evidence to support this view. The authors concluded that confusion of $M$. catarrhalis with Neisseria spp., especially the harmless $N$. cinerea (present in $90 \%$ of throats), was probably responsible for the original misconception that $M$. catarrhalis is predominantly a commensal organism.

Upper respiratory tract infections caused by $M$. catarrhalis present as otitis media or sinusitis and are most common in children [21]. M. catarrhalis is the third most common cause of either condition after $S$. pneumoniae and $H$. influenzae $[21,22]$, and can be cultured from up to $16 \%$ of middle ear effusions from children with otitis media [21]. Organisms from the nasopharynx can spread easily to the middle ear, and strains of $M$. catarrhalis that are indistinguishable by restriction endonuclease analysis (REA) have been demonstrated in the nasopharynx and middle ear of seven of eight children with otitis media [23]. Otitis media is very common in children, with nearly $50 \%$ of all children estimated to have had at least one episode of the disease by the age of 1 year, rising to $70 \%$ by the age of 3 years [24]. Maxillary sinusitis is less well understood than otitis media, but is similar in its pathogenesis and microbiology. Many children suffer a degree of sinusitis during the course of an upper respiratory tract infection - although this may present as nothing more than a runny nose - and the necessity for antimicrobial treatment is uncertain [21]. Wald et al. [25] studied maxillary sinus aspirates from 30 children with upper respiratory tract symptoms and abnormal maxillary radiographs. The three common respiratory pathogens, i.e., $S$. pneumoniae, $H$ influenzae and $M$. catarrhalis, were isolated from 34 of 47 sinus aspirates, often in combination. M. catarrhalis accounted for $22 \%$ of all isolates, but was more likely to be found in pure culture and in younger children. A poor correlation was found between the presence of a species in sinus aspirates and its presence in cultures of the nasopharynx or throat. In a different study, $M$. catarrhalis was isolated from aspirates taken from young adults with acute maxillary sinusitis at a much lower frequency of $2 \%$ [26].

The most common cause of morbidity due to $M$. catarrhalis in adults is exacerbation of chronic bronchitis in patients with pre-existing pulmonary disease [27]. $M$. catarrhalis is also the third most commonly isolated pathogen from the lower respiratory tract after $S$. pneumoniae and $H$. influenzae, and is often isolated in conjunction with one of these two pathogens. Slevin et al. [27] studied 101 patients with $M$. catarrhalis isolates from sputum, all judged to be clinically significant on the basis of sputum purulence, fever, chest X-ray appearance and peripheral leucocytosis. Of the 101 patients, 59 had reasons for general immunosuppression, while 94 had either chronic chest disease or a history of smoking. $M$. catarrhalis was isolated in pure culture from 71 patients, and in combination with other pathogens from 30 patients. As discussed previously, the pathogenic role of $M$. catarrhalis in such patients has not always been accepted and further validation of this has been required. Isolation of an organism from trans-tracheal aspirates provides good evidence that its presence in sputum is not a result of oropharyngeal contamination of lower respiratory tract secretions. Trans-tracheal aspirations were performed by Ninane et al. [28] on 193 miners with acute exacerbations of chronic bronchitis. These workers found $M$. catarrhalis to be the third commonest isolate after $H$. influenzae (44 isolates) and $S$. pneumoniae (22 isolates), with 14 pure cultures of $M$. catarrhalis and one mixed with $H$. influenzae. Thornley et al. [29] took trans-tracheal aspirates from 11 symptomatic patients with $M$. 
catarrhalis in their sputum and confirmed the presence of the organism in the lower respiratory tract in 10 patients, of whom four yielded pure cultures of $M$. catarrhalis [29]. Lastly, a case control study that compared patients with $M$. catarrhalis isolated from expectorated sputum against controls with commensal Neisseria isolates confirmed an association between $M$. catarrhalis and the clinical features of bronchopulmonary infection [30]. Thus, there is good evidence to support the view that $M$. catarrhalis is a respiratory pathogen. Lower respiratory tract infection with $M$. catarrhalis is more likely to affect elderly patients and is more common in winter [31]. There is some evidence that, even in the absence of changes in laboratory technical or interpretive practices, the incidence of $M$. catarrhalis respiratory infection is increasing [32, 33].

Although exacerbation of chronic bronchitis is the commonest manifestation of $M$. catarrhalis infection, pneumonia may also occur. Wright et al. [34] described 42 cases of pneumonia diagnosed on the basis of a pure culture of $M$. catarrhalis from sputum together with the presence of a new infiltrate on chest $\mathrm{X}$-ray or autopsy evidence of pneumonia. These patients were predominantly elderly with a serious underlying disease and, although the pneumonia itself was described as a mild illness, $45 \%$ of the patients died of their underlying disease within 3 months. $M$. catarrhalis pneumonia is therefore associated with a poor prognosis. Bacterial tracheitis is a further rare manifestation of $M$. catarrhalis infection which has been reported several times in children, sometimes in association with respiratory syncytial virus infection [35-37].

Invasive disease caused by $M$. catarrhalis is relatively uncommon, but is well-documented in the literature. Catlin [1] extensively reviewed the evidence that $M$. catarrhalis has caused meningitis, bacteraemia and endocarditis. It is difficult to assess the accuracy of strain identification in many older reports, but it seems likely that $M$. catarrhalis has been responsible for all of the above conditions at some time. In particular, there is good evidence that $M$. catarrhalis is an occasional cause of bacteraemia [38], with episodes reported in association with pneumonia [39], otitis media [40] and AIDS [41]. Analysis of $M$. catarrhalis bacteraemia reports made by laboratories in England and Wales to the Communicable Diseases Surveillance Centre, Colindale, London reveals a total of 89 cases over the 4 years from 1992 to 1995 inclusive (Table 1) [42]. The age distribution for 87 of these patients (Fig. 2a) shows that infection was commonest in children aged $<10$ years, with $46 \%$ of cases in this age range. Further analysis of the latter group (Fig. 2b) shows that cases peak at the age of 1 year and tail off by the age of 5 years, although there were four cases in babies aged $\leqslant 10$ days. Over the entire age range, there were similar numbers of cases in
Table 1 Number of cases of $M$. catarrhalis bacteraemia reported to the Communicable Diseases Surveillance Centre, Colindale, London by laboratories in England and Wales, 1992-1995

\begin{tabular}{lc}
\hline Year & Number of reported cases \\
\hline 1992 & 21 \\
1993 & 26 \\
1994 & 20 \\
1995 & 22 \\
\hline
\end{tabular}

males (43) and females (45), with one case of unknown sex. Insufficient clinical details are available to categorise these patients with regard to underlying disease, but many had predisposing conditions, e.g., leukaemia, congenital heart disease, cystic fibrosis or prematurity. Isolates from these cases are not available to enable confirmation of bacteriological identity, but it is likely that any false-positive identifications would be balanced by under-reporting of such episodes, and several cases reported as bacteraemia associated with Moraxella or Branhamella spp. were not included in the survey. These figures demonstrate that $M$. catarrhalis bacteraemia is a well-recognised clinical entity. The predominance of this infection in young children is perhaps surprising, but may be related to the high carriage rates of $M$. catarrhalis in this age group [18-20]. Other possible contributory factors will be discussed later. Invasive disease other than bacteraemia is unusual, but a case of acute purulent pericarditis caused by $M$. catarrhalis has been recorded [43].

\section{Nosocomial infection}

There is now convincing evidence that the spread of $M$. catarrhalis within hospital wards can lead to significant outbreaks of nosocomial infection. Epidemiological evidence for this was presented by Ahmad et al. [44], but these authors were unable to confirm their suspicions because of the absence at that time of a suitable typing system. Patterson et al. [45] applied REA to isolates from an apparent outbreak in an intensive care setting and confirmed isolation of the same strain from five patients and two staff members, all of whom were symptomatic. We have also found good evidence of nosocomial spread of $M$. catarrhalis, with significant correlations between length of hospital stay and acquisition of $M$. catarrhalis. In these studies, SDS-PAGE and immunoblotting of $M$. catarrhalis whole cell proteins [46], and REA of bacterial DNA [46-48] demonstrated considerable genetic heterogeneity among strains of $M$. catarrhalis, but epidemiologically related isolates were more likely to be indistinguishable, and several clusters of apparent nosocomial infection in respiratory wards were identified. Carriage and spread of $M$. catarrhalis by ward staff is a possible route of infection, but it was not possible to demonstrate this directly, although indistinguishable $M$. catarrhalis strains were isolated from 

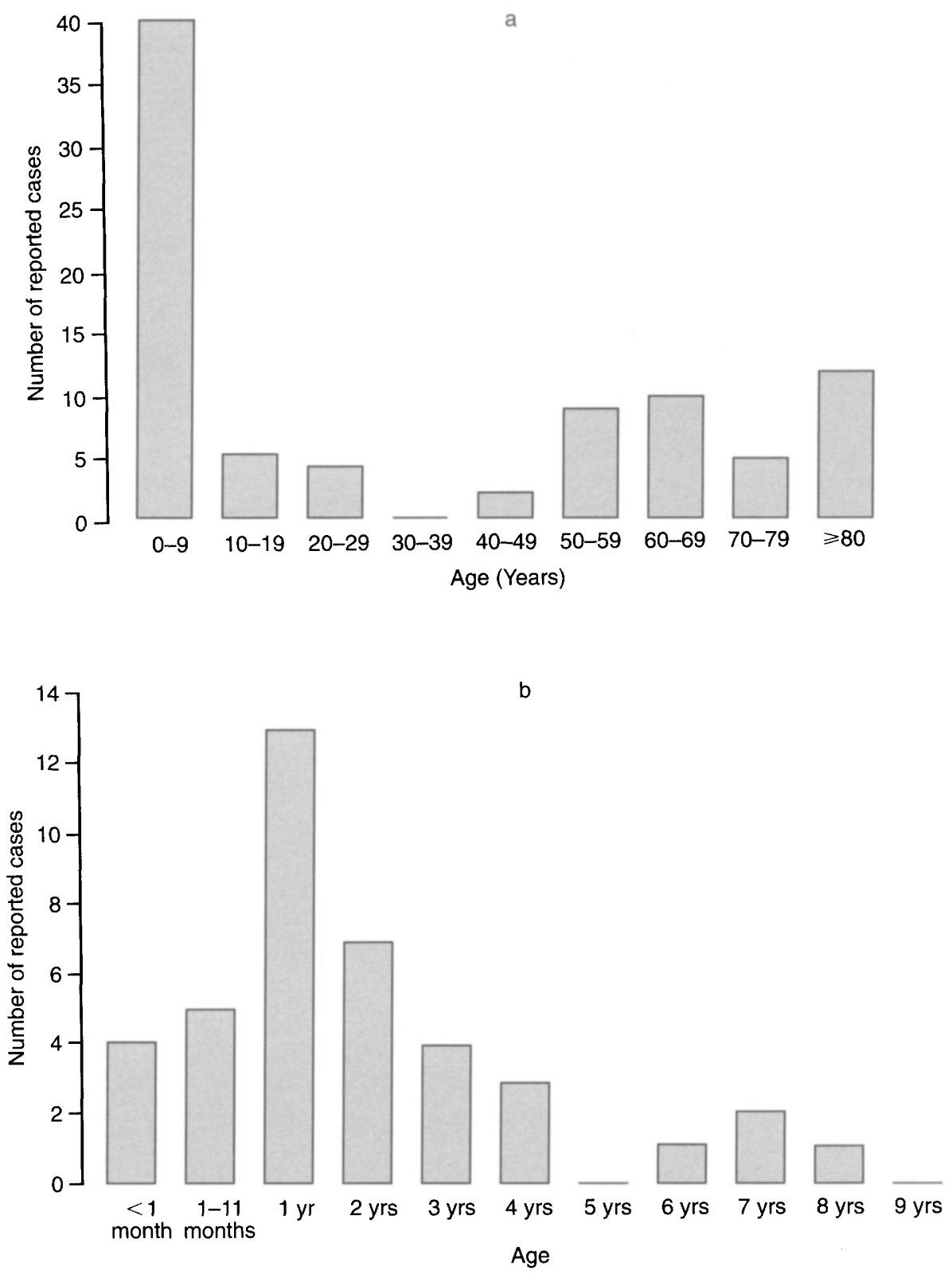

Fig. 2. a, Age distribution of 87 patients with M. catarrhalis bacteraemia; b, age distribution of 40 children under the age of 10 years with $M$. catarrhalis bacteraemia.

patients and settle plates placed in the same ward (personal unpublished data). Similar studies by Ikram et al. [49] also show persistence of the organism in the environment and an association between $M$. catarrhalis acquisition in hospital and length of stay.

\section{Antibiotic susceptibility}

\section{Resistance to $\beta$-lactam antibiotics}

A retrospective study in the USA of $18 M$. catarrhalis isolates dating from 1952 to 1975 found no $\beta$ lactamase-producing strains before the first $\beta$-lactamase-positive isolates in 1976 [50]. Similarly, 46 French isolates dating from 1970 to 1976 were found to be $\beta$-lactamase-negative [51], with the first $\beta$ lactamase-positive French isolate reported in 1977 [52].
The subsequent increase in incidence of $\beta$-lactamasepositive $M$. catarrhalis isolates has been described as the fastest increase in prevalence of any known $\beta$ lactamase within a bacterial species [53]. Surveys of resistance in the UK in 1991, and in Denmark in 1994, showed that $91 \%$ and $84 \%$ of $M$. catarrhalis strains, respectively, were $\beta$-lactamase-positive $[19,54]$. The reason for the dramatic emergence of $\beta$-lactamaseproducing strains is not clear, and although it has been attributed to increased prescribing of $\beta$-lactam antibiotics, increases in the prevalence of $\beta$-lactamasepositive strains of other comparable species such as $N$. gonorrhoeae or $H$. influenzae have not been nearly so spectacular.

M. catarrhalis $\beta$-lactamases are of two types which can be distinguished by isoelectric focusing $[52,55]$ 
and, as they are quite different from $\beta$-lactamase enzymes in any other genus, their original source is unknown [53]. The two enzymes are phenotypically similar and have been designated BRO-1 (previously called Ravasio type) and BRO-2 (previously called 1908-type), the name deriving from Branhamella and Moraxella [50]. BRO-1 is the most common and is present in c. $90 \%$ of $\beta$-lactamase-positive strains [51, $56,57]$. Strains with the BRO- $1 \beta$-lactamase have $25-$ fold higher ampicillin MICs than $\beta$-lactamase-negative strains, while in those strains with the BRO-2 enzyme, ampicillin MICs are only four-fold higher than in $\beta$ lactamase negative strains [57]. It is thought that this difference is caused by higher levels of production of the BRO-1 enzyme (2-3-fold more than BRO-2) rather than any intrinsic difference in enzyme activity [53].

BRO $\beta$-lactamases are found only in $M$. catarrhalis and in two closely related species, $M$. lacunata [50] and $M$. nonliquefaciens $[50,58]$. Conjugal transfer of BRO $\beta$-lactamase from one $M$. catarrhalis strain to another was demonstrated by Kamme et al. [59]. Transfer from $M$. nonliquefaciens to $M$. catarrhalis has also been demonstrated $[59,60]$. The genetics of $\beta$-lactamase production in $M$. catarrhalis are poorly understood. Both BRO-1 and BRO-2 genes are thought to be chromosomal, although it has been proposed that both enzymes are the product of one gene and derive from a membrane-bound precursor enzyme [61]. Claims that the genes are plasmid-borne [62] have not been supported by other investigators, but there is no doubting the efficiency with which the enzyme has spread throughout the species population, leading to the suggestion that the genes are on a conjugal transposon [53]. The involvement of nonpathogenic Moraxella spp. in the gene pool may be significant in promoting spread, as widespread carriage of such organisms increases the opportunity for genetic exchange [63]. Other than the enzymes discussed above, there have been single reports of a further $\beta$-lactamase, designated BRO-3 [64], and of a strain with a plasmid-mediated TEM- $\beta$-lactamase [65].

Antimicrobial susceptibility testing of $M$. catarrhalis reveals a bimodal distribution of MIC values of ampicillin among $\beta$-lactamase-positive strains, probably reflecting the presence of two populations with different $\beta$-lactamase enzymes [54]. However, disk testing for sensitivity to ampicillin is problematic, as many $\beta$-lactamase-positive strains show large zones of inhibition and would be classed as sensitive according to normal test procedures $[53,54]$. The clinical significance of this is uncertain, but in the absence of extensive trials, it is probably better to err on the side of caution in routine practice and to test isolates that are apparently sensitive by standard disk sensitivity tests for the presence of $\beta$-lactamase by a chromogenic method. Both research groups that high- lighted this problem have recommended that, whatever the results of disk sensitivity tests, all $\beta$-lactamasepositive isolates should be reported as ampicillin- or amoxycillin-resistant [53, 54].

There is evidence that $M$. catarrhalis $\beta$-lactamases can protect other respiratory pathogens from $\beta$-lactam antibiotics when present in mixed infections. Hol et $a l$. [66] inoculated mice intranasally with $S$. pneumoniae and either $\beta$-lactamase-positive or -negative $M$. catarrhalis. Treatment with penicillin or amoxycillin was ineffective for those mice inoculated with $\beta$ lactamase-positive $M$. catarrhalis, leading to death resulting from pneumococcal pneumonia. Treatment with amoxycillin and clavulanic acid (a $\beta$-lactamase inhibitor) proved an effective treatment regimen for these mice. There is also clinical evidence that this socalled 'indirect pathogenicity' of $M$. catarrhalis can result in treatment failure when mixed infections of $\beta$ lactamase-positive $M$. catarrhalis and $\beta$-lactam-sensitive strains of $S$. pneumoniae or $H$. influenzae are treated with a $\beta$-lactamase-sensitive penicillin [67].

Several other pathogens, such as $S$. pneumoniae, $H$. influenzae and $N$. gonorrhoeae, have developed other mechanisms of resistance to $\beta$-lactams, most commonly by altering the structure of their penicillinbinding proteins. There is no evidence at present of any such clinically significant resistance mechanism in M. catarrhalis, but Catlin [1] has commented on the range of MICs of $\beta$-lactam agents found in $\beta$ lactamase-negative $M$. catarrhalis strains. It is important to continue to monitor the sensitivities of $\beta$ lactamase-negative strains in order to detect the emergence of any such phenomenon.

\section{Resistance to non- $\beta$-lactam antibiotics}

Other than $\beta$-lactamase-mediated resistance to penicillins and inherent resistance to trimethoprim, $M$. catarrhalis remains generally sensitive to macrolide, cephalosporin and tetracycline antibiotics [54,68]. It is also normally sensitive to co-amoxyclav. Erythromycinresistant strains have been reported occasionally [27, 69] and co-trimoxazole is reported to be effective despite resistance to its trimethoprim component [69]. Fung et al. [54] reported that $6.5 \%$ of their strains were resistant to sulphamethoxazole. $M$. catarrhalis strains are almost universally susceptible to tetracycline, although two pairs of strains isolated from Texas and England [70] were tetracycline-resistant because of the presence of a non-transferable TetB determinant. Resistant strains have also been isolated in Spain [65] and China [71]. Roberts et al. [70] suggested that the TetB determinant may have transferred from Haemophilus spp. by conjugation or transformation. Aminoglycoside resistance has been observed, with one study reporting $17 \%$ streptomycin resistance in Spanish isolates and smaller numbers of kanamycin- and neomycin-resistant isolates [55]. 


\section{Typing methods}

Until relatively recently there was no established, discriminatory typing system for $M$. catarrhalis strain differentiation. Phenotypic methods such as serotyping [72], isoelectric focusing of $\beta$-lactamase enzymes [56], bacteriocin typing [73], SDS-PAGE of outer-membrane proteins (OMPs) [74], esterase electrophoresis [75] and gel electrophoresis of soluble proteins [76] have all been used with varying degrees of success. A range of phenotypic characteristics, including serum resistance, haemagglutination, $\beta$-lactamase production and antimicrobial susceptibility pattern, was used by Soto-Hernandez et al. [77] to discriminate between $M$. catarrhalis strains. However, none of these phenotypic methods has provided a high level of discrimination between closely related strains.

The first genotypic method relied on analysis of plasmid DNA [78], but proved unsuccessful because of the small number of plasmids found. A chromosomal DNA-based typing method (REA) was used by Patterson et al. [45] to confirm a suspected outbreak of nosocomial infection. In this method, chromosomal DNA is purified and cleaved with restriction endonucleases to provide strain-specific fingerprints which are resolved on agarose gels. REA proved highly discriminatory for isolates of $M$. catarrhalis in this study although the method was not compared to other typing schemes. We have successfully used three methods for the investigation of suspected nosocomial infection: SDS-PAGE of whole cell polypeptides; immunoblots of these gels with normal human serum; and REA with the frequently cutting enzyme $T a q \mathrm{I}$ [46-48]. In subsequent studies (personal unpublished results), we have used pulsed-field gel electrophoresis (PFGE) with the rare-cutting enzymes NotI and SmaI. PFGE is similar to REA, except that fewer DNA fragments are obtained because of the use of restriction endonucleases that cut less frequently. The large fragments of DNA produced cannot be resolved by conventional gel electrophoresis, but separation can be achieved by switching the direction of the electric current continuously to allow the resolution of DNA fragments from $c$. $50 \mathrm{~kb}$ to several megabases in length. PFGE with NotI and SmaI has also been used by a Japanese group to type 38 hospital isolates of $M$. catarrhalis [79]. Their results suggest that this method is highly suitable for use in typing studies and the publication of recommended criteria for the more general application of PFGE to bacterial typing may lead to this becoming the molecular method of choice [80].

\section{Population genetics}

To date there have been no published studies on the population genetics of $M$. catarrhalis. Studies on other organisms, such as Escherichia coli [81], have attempted to assess whether an organism has a clonal population structure. In a clonal population, genetic recombination between strains or other species is undetectable and changes to the bacterial genome are thought to occur by mutation and localised DNA rearrangement [82]. Clonal populations are characterised by the existence of similar strains separated in time and space, e.g., strains isolated years apart from different countries. Non-clonal populations arise when recombination between strains or other species occurs frequently. This type of population is genetically heterogeneous with little identity between strains, even those from similar sources. The method chosen to examine the genetics of a population is very important, as the greater the discriminatory power of the technique used, the more accurate will be the results obtained. We have performed a limited study of $M$. catarrhalis population genetics with REA, PGFE and multi-locus enzyme electrophoresis (MLEE). MLEE, which is the most commonly used method in the study of bacterial population genetics, relies on comparisons of the electrophoretic mobility of known proteins, giving information (indirectly) about the strain at the genetic level. Preliminary results (personal unpublished results) suggest that most $M$. catarrhalis isolates are different from each other, but we have found occasional isolates obtained from different countries several years apart which are indistinguishable by all methods used. This leads us to believe that $M$. catarrhalis may have a similar population structure to that found in $N$. meningitidis, i.e., one with a non-clonal structure, but with the occasional emergence of a successful 'epidemic' clone.

\section{Pathogenicity and virulence}

As $M$. catarrhalis has become accepted more widely as a pathogen, interest in potential virulence factors has increased. Endotoxin or lipopolysaccharide (LPS) plays a major role in the pathogenesis of gramnegative infection and therefore presents an obvious area for study. In $N$. gonorrhoeae, LPS is associated with membrane vesicles or blebs. Similar vesicles are found in $M$. catarrhalis broth culture supernates [83] and three major serotypes of $M$. catarrhalis LPS have been described by Vanechoutte et al. [72], accounting for $95 \%$ of all strains. The LPS of $M$. catarrhalis, like those of $N$. meningitidis and $N$. gonorrhoeae, does not have the long O-antigen side chains characteristic of the Enterobacteriaceae, and the oligosaccharide structure that determines the antigenic differences between the three serotypes has been studied extensively. The inner core contains branched polysaccharides with a common terminal $\alpha$-D-Gal-(14)- $\beta$-D-Gal (1-4)- $\alpha$-Glc epitope [84]. The terminal residues that determine the serotypes are $\alpha$-DGlcNAc-(1-2)- $\beta$-D-Glc for serotype A $[84,85], \beta$-DGal-(1-4)- $\beta$-D-Glc for serotype B [86], and $\beta$-D-Gal(1-4)- $\alpha$-D-GlcNAc for serotype $C$ [87]. There is some 
cross-reaction between serotypes, particularly between serotypes $\mathrm{A}$ and $\mathrm{C}[72,86]$. In a study with an animal model, formalin-killed isolates of $M$. catarrhalis were shown to produce effusions in the middle ear of chinchilla, indicating a possible role for endotoxin in the disease process [88]. Storm Fomsgaard et al. [89] also found that $M$. catarrhalis LPS had a similar effect to enterobacterial LPS in mice and in the Limulus amoebocyte lysate assay.

Pili or fimbriae are protein filaments that extend from the surface of bacteria and have a role in adherence to host mucosal epithelial cells [90]. Fimbriae have been found in some, but not all, strains of $M$. catarrhalis [91]. Adherence of the bacterium to respiratory mucosal cells is a primary step in the pathogenesis of infection and prevents the organism from being washed away by the mucociliary escalator. Hybridisation with a pilus gene from $M$. bovis showed the existence of class 4 pilus genes in four $M$. catarrhalis strains [91]. This class of pilus is present in other pathogenic bacteria, such as $N$. gonorrhoeae [92, 93], N. meningitidis [94], Pseudomonas aeruginosa [95] and Vibrio cholerae [96], as well as other pathogenic Moraxella spp. [94, 97, 98]. Electron microscopy by Marrs and Weir [91] indicated the presence of at least one other pilus class in $M$. catarrhalis, as is common in other bacterial species [99]. Other investigators have demonstrated the presence of non-type 4 fimbriae both in vitro [100, 101] and in vivo [102]. Recent studies of the nature of the receptor that mediates adherence of $M$. catarrhalis to the respiratory epithelium suggest that fimbrial adherence involves interaction with a specific glycosphingolipid receptor [103]. Identification of a specific receptor that mediates adherence opens up the possibility of inhibiting the binding of $M$. catarrhalis to the mucosal surface and thus preventing colonisation and subsequent infection.

Complement plays an important role in host defences against $N$. meningitidis and $N$. gonorrhoeae, as illustrated by two studies which showed that patients deficient with respect to complement were about 8000 -fold more likely to acquire an infection by these organisms [104, 105]. Resistance to the action of complement is therefore an important virulence factor, especially in gram-negative pathogens [106]. There is good evidence that some $M$. catarrhalis strains produce a protein that interferes with the formation of the membrane attack complex of complement and thus renders the organism 'serum resistant' [107]. Helminen et al. [108] showed that a genetically manipulated $M$. catarrhalis strain which does not express the CopB OMP lacks the serum resistance of the parent strain, but that this property returns with restoration of gene expression. A survey of strains carried by healthy schoolchildren and isolated from adults with lower respiratory tract infections showed differences in the prevalence of serum resistance in these different groups [109]. Serum-resistant strains were more likely to be found in younger children and in symptomatic adults than in older children. Hol et al. [109] did not study carriage in children aged $<4$ years, but it is interesting to speculate that the peak incidence of $M$. catarrhalis bacteraemia in younger children discussed earlier may be associated with an increased incidence in the carriage of serum-resistant strains.

Human pathogens require iron to grow and differentiate, yet the blood and mucosae of man are ironlimited environments because of the binding of iron by human transferrin in serum and lactoferrin in mucus. Pathogenic bacteria have therefore evolved several mechanisms for iron-uptake, commonly involving the production of siderophores. These are secreted compounds that chelate iron in the environment and are then taken up by specific OMP receptor proteins [110, 111]. However, siderophores are not produced by Neisseria spp. or $M$. catarrhalis, and these organisms have developed different mechanisms for iron-uptake. $M$. catarrhalis, $N$. gonorrhoeae and $N$. meningitidis have transferrin and lactoferrin receptors present on their cell surfaces that remove bound iron from the human carrier protein before uptake into the bacterial cell $[112,113]$. Campagnari et al. [114] showed that new OMPs, but not siderophores, are expressed if $M$. catarrhalis strains are grown in the absence of iron, and postulated that these proteins are important for the acquisition of iron in vivo.

Possession of a capsule is an important virulence mechanism for many organisms, usually preventing phagocytosis. There have been reports of a polysaccharide capsule in $M$. catarrhalis similar to that of $N$. gonorrhoeae [115-118], but this has not been welldefined. One further possible virulence mechanism is suggested by a study of five bacterial species, including $M$. catarrhalis, in infection of the lower respiratory tract. This showed that $M$. catarrhalis synthesises clinically significant amounts of histamine, as do $P$. aeruginosa and $H$. influenzae [119]. Histamine is involved in restriction of the airways resulting from smooth muscle contraction and slowing of ciliary beat in vitro [120], leading to a depressed rate of mucus clearance and increased colonisation of the respiratory tract.

\section{Host responses}

Serological evidence for infection by $M$. catarrhalis was presented by Eliasson [121], who found antibodies to $\mathrm{P}$ antigen in most healthy adult sera. Goldblatt et al. [122] demonstrated that the IgG response to $M$. catarrhalis in children increases after the age of 1 year, but the predominant response to OMPs is in the IgG3 subclass and does not appear until after the age of 4 years. The delayed appearance of antibody to 
OMPs may be a further factor that contributes to the predominance of $M$. catarrhalis bacteraemia in children aged $<4$ years. Although antibody to protein antigens is most commonly found in the IgG1 subclass, the IgG3 isotype is often found in responses against virus proteins and $H$. influenzae OMPs. The IgG3 response to $M$. catarrhalis OMPs has been confirmed by other investigators [123]. Unlike $H$. influenzae, OMPs in $M$. catarrhalis show little strain-to-strain variation [124]. The conserved nature of these proteins has raised interest in the possibility that one or more might form the basis of a protective vaccine. Helminen et al. [125] reported a monoclonal antibody (MAb) specific for a $300-400-\mathrm{kDa}$ surface antigen (UspAP) that enhanced pulmonary clearance of the organism in passively immunised mice. Recombinant antigen was recognised in immunoblots by convalescent serum, but not acute phase serum, from patients with $M$. catarrhalis pneumonia. Antibody responses to the CopB antigen [126] and to the 84-kDa antigen OMP B1 have also been demonstrated in patients with $M$. catarrhalis infections [127]. A further possible vaccine candidate is the heat-modifiable OMP C/D, which is also expressed on the surface of the intact bacterium [128]. Antibodies to LPS have been measured in patients with $M$. catarrhalis lower respiratory infections, but do not appear to show a serotype-specific response [129].

\section{Conclusions}

Since its initial recognition at the start of the century, and following a long intervening period of neglect, M. catarrhalis has now been rediscovered as a pathogen. In terms of clinical significance, it clearly comes third in the respiratory tract after $S$. pneumoniae and $H$. influenzae, but the impact of immunisation for both these species may disturb this balance in years to come. Lower respiratory tract infection in patients with underlying chest disease is the best known example of its clinical impact, but the potential of the organism to cause nosocomial infection is less well recognised. Otitis media in children caused by $M$. catarrhalis represents significant morbidity in simple numerical terms and may contribute to hearing problems in later life. The epidemiology of $M$. catarrhalis bacteraemia deserves further study in order to confirm the findings presented here of a peak in children aged between 1 and 2 years. Current work is now focusing on molecular aspects of the organism's epidemiology and pathogenicity. As it becomes more fully understood, the prevention of infection by $M$. catarrhalis may become possible. Vaccine targets include the highly conserved major OMPs, while interference with fimbrial adherence may also provide options for therapy or prevention. The speed with which this organism acquired the ability to produce $\beta$ lactamase warns us that this is a pathogen which should not be under-rated.
We are grateful to Dr S. Handysides, CDR Editor, for permission to report the analysis of $M$. catarrhalis bacteraemia.

\section{References}

1. Catlin BW. Branhamella catarrhalis: an organism gaining respect as a pathogen. Clin Microbiol Rev 1990; 3: 293-320.

2. Berk SL. From Micrococcus to Moraxella: the reemergence of Branhamella catarrhalis. Arch Intern Med 1990; 150: 2254-2257.

3. Frosch P, Kolle W. Die Mikrokokken. In: Flugge C (ed) Die Mikroorganismen. Leipzig, Germany, Verlag von Vogel. 1896: $154-155$.

4. Seifert O. Sammlungs Klinischer Vortrage, Leipzig, Germany. 1882; 240: 21

5. Ghon A, Pfeiffer H. Der Mikrococcus catarrhalis (R. Pfeiffer) als Krankheitserreger. Z Klin Med 1902; 44: 263-281.

6. Dunn RA, Gordon MH. Clinical and bacteriological aspects of an epidemic simulating influenza. $B M J 1905 ; 2$ : $421-427$.

7. Gordon JE. The gram-negative cocci in colds and influenza. Influenza studies VII. J Infect Dis 1921; 29: 462-494.

8. Bøvre K. The genus Moraxella. In: Krieg NR, Holt JG (eds) Bergey's Manual of systematic bacteriology, vol 1. Baltimore, USA, Williams and Wilkins. 1984: 296-303.

9. Catlin BW. Transfer of the organism named Neisseria catarrhalis to Branhamella gen. nov. Int $J$ Syst Bacteriol 1970; 20: 155-159.

10. Véron $M$, Lenvoisé-Furet $A$, Coustère $C$, Ged C, Grimont $F$. Relatedness of three species of "false Neisseria", Neisseria caviae, Neisseria cuniculi, and Neisseria ovis, by DNA-DNA hybridizations and fatty-acid analysis. Int $J$ Syst Bacteriol 1993; 43: $210-220$.

11. Rossau R, Van Landschoot A, Gillis M, De Ley J. Taxonomy of Moraxellaceae fam. nov., a new bacterial family to accommodate the genera Moraxella, Acinetobacter, and Psychrobacter and related organisms. Int J Syst Bacteriol 1991; 41: 310-319.

12. Enright MC, Carter PE, MacLean IA, McKenzie $H$. Phylogenetic relationships between some members of the genera Neisseria, Acinetobacter, Moraxella, and Kingella based on partial $16 \mathrm{~S}$ ribosomal DNA sequence analysis. Int $J$ Syst Bacteriol 1994; 44: 387-391.

13. General Discussion: Section 1. Drugs 1986; 31 Suppl 3: 38-39.

14. Ahmad F, Young H, McLeod DT, Croughan MJ, Calder MA. Characterisation of Branhamella catarrhalis and differentiation from Neisseria species in a diagnostic laboratory. $J$ Clin Pathol 1987; 40: 1369-1373.

15. Young H, Harris AB, Tapsall JW. Differentiation of gonococcal and non-gonococcal neisseriae by the superoxol test. $\mathrm{Br} J$ Vener Dis 1984; 60: 87-89.

16. Riley TV. A note on hydrolysis of tributyrin by Branhamella and Neisseria. J Appl Bacteriol 1987; 62: 539-542.

17. Peiris V, Ralphson K, Norris S, Bennett C. Not Branhamella catarrhalis: misidentification of oxidase-positive, Gram-negative cocci isolated from the genital tract. $J$ Infect 1993; 27: 338-339.

18. Faden H, Harabuchi Y, Hong JJ and Tonawanda/Williamsville Pediatrics. Epidemiology of Moraxella catarrhalis in children during the first 2 years of life: relationship to otitis media. $J$ Infect Dis 1994; 169: 1312-1317.

19. Ejlertsen T, Thisted E, Ebbesen F, Olesen B, Renneberg J. Branhamella catarrhalis in children and adults. A study of prevalence, time of colonisation, and association with upper and lower respiratory tract infections. $J$ Infect 1994; 29: 23-31.

20. Vaneechoutte M, Verschraegen G, Claeys G, Weise B, van den Abeele AM. Respiratory tract carrier rates of Moraxella (Branhamella) catarrhalis in adults and children and interpretation of the isolation of $M$. catarrhalis from sputum. $J$ Clin Microbiol 1990; 28: 2674-2680.

21. Bluestone CD. Otitis media and sinusitis in children. Role of Branhamella catarrhalis. Drugs 1986; 31 Suppl 3: 132-141.

22. Pichichero ME, Pichichero CL. Persistent acute otitis media: 1. Causative pathogens. Pediatr Infect Dis $J$ 1995; 14; 178-183.

23. Dickinson DP, Loos BG, Dryja DM, Bernstein JM. Restric- 
tion fragment mapping of Branhamella catarrhalis: a new tool for studying the epidemiology of this middle ear pathogen. J Infect Dis 1988; 158: 205-208.

24. Thoene DE, Johnson CE. Pharmacotherapy of otitis media. Pharmacotherapy 1991; 11: 212-221.

25. Wald ER, Milmoe GJ, Bowen A'D, Ledesma-Medina J, Salamon N, Bluestone CD. Acute maxillary sinusitis in children. $N$ Engl J Med 1981; 304: 749-754.

26. Jousimies-Somer HR, Savolainen S, Ylikoski JS. Bacteriological findings of acute maxillary sinusitis in young adults. $J$ Clin Microbiol 1988; 26: 1919-1925.

27. Slevin NJ, Aitken J, Thornley PE. Clinical and microbiological features of Branhamella catarrhalis bronchopulmonary infections. Lancet 1984; 1: 782-783.

28. Ninane G, Joly J, Kraytman M. Bronchopulmonary infection due to Branhamella catarrhalis: 11 cases assessed by transtracheal puncture. BMJ 1978; 1: 276-278.

29. Thornley PE, Aitken J, Drennan CJ, MacVicar J, Slevin NJ. Branhamella catarrhalis infection of the lower respiratory tract: reliable diagnosis by sputum examination. $B M J 1982$ 285: $1537-1538$.

30. Yuen KY, Seto WH, Ong SG. The significance of Branhamella catarrhalis in bronchopulmonary infection - a casecontrol study. J Infect 1989; 19: 251-256.

31. DiGiovanni C, Riley TV, Hoyne GF, Yeo R, Cooksey P. Respiratory tract infections due to Branhamella catarrhalis. epidemiological data from Western Australia. Epidemio Infect 1987; 99: 445-453.

32. McLeod DT, Ahmad F, Power JT, Calder MA, Seaton A Bronchopulmonary infection due to Branhamella catarrhalis BMJ 1983; 287: 1446-1447.

33. McLeod DT, Ahmad F, Capewell S, Croughan MJ, Calder MA, Seaton A. Increase in bronchopulmonary infection due to Branhamella catarrhalis. BMJ 1986; 292: 1103-1105.

34. Wright PW, Wallace RJ, Shepherd JR. A descriptive study of 42 cases of Branhamella catarrhalis pneumonia. Am J Med 1990; 88: Suppl 5A: 2S-8S.

35. Ernst TN, Philp M. Bacterial tracheitis caused by Branhamella catarrhalis. Pediatr Infect Dis J 1987; 6: 574.

36. Wong VK, Mason WH. Branhamella catarrhalis as a cause of bacterial tracheitis. Pediatr Infect Dis $J$ 1987; 6: 945-946.

37. Alligood GA, Kenny JF. Tracheitis and supraglottis associated with Branhamella catarrhalis and respiratory syncytial virus. Pediatr Infect Dis $J$ 1989; 8: 190-191.

38. Meyer GA, Shope TR, Waecker NJ, Lanningham FH. Moraxella (Branhamella) catarrhalis bacteremia in children A report of two patients and review of the literature. Clin Pediatr 1995; 34: 146-150.

39. Collazos J, de Miguel J, Ayarza R. Moraxella catarrhalis bacteremic pneumonia in adults: two cases and review of the literature. Eur $J$ Clin Microbiol Infect Dis 1992; 11 237-240.

40. Alaeus A, Stiernstedt G. Branhamella catarrhalis septicemia in an immunocompetent adult. Scand J Infect Dis 1991; 23 $115-116$.

41. Wong VK, Ross LA. Branhamella catarrhalis septicemia in an infant with AIDS. Scand J Infect Dis 1988; 20: 559-560.

42. CDR Weekly Reports, London, Communicable Disease Surveillance Centre. 1992-1995.

43. Kostiala AAI, Honkanen T. Branhamella catarrhalis as a cause of acute purulent pericarditis. $J$ Infect 1989; 19 291-292.

44. Ahmad F, McLeod DT, Power JT, Calder MA. Branhamella catarrhalis prevalence in a hospital population. J Hosp Infect 1985; 6: 71-74.

45. Patterson TF, Patterson JE, Masecar BL, Barden GE, Hierhalzer WJ, Zervos MJ. A nosocomial outbreak of Branhamella catarrhalis confirmed by restriction endonuclease analysis. J Infect Dis 1988; 157: 996-1001.

46. McKenzie H, Morgan MG, Jordens JZ, Enright MC, Bain M. Characterisation of hospital isolates of Moraxella (Branhamella) catarrhalis by SDS-PAGE of whole-cell proteins, immunoblotting and restriction-endonuclease analysis. $J$ Med Microbiol 1992; 37: 70-76.

47. Morgan MG, McKenzie H, Enright MC, Bain M, Emmanuel FXS. Use of molecular methods to characterize Moraxella catarrhalis strains in a suspected outbreak of nosocomial infection. Eur J Clin Microbiol Infect Dis 1992; 11: 305-312.

48. Richards SJ, Greening AP, Enright MC, Morgan MG,
McKenzie H. Outbreak of Moraxella catarrhalis in a respiratory unit. Thorax 1993; 48: 91-92.

49. Ikram RB, Nixon M, Aitken J, Wells E. A prospective study of isolation of Moraxella catarrhalis in a hospital during the winter months. J Hosp Infect 1993; 25: 7-14.

50. Wallace RJ, Steingrube VA, Nash DR et al. BRO $\beta$ lactamases of Branhamella catarrhalis, and Moraxella subgenus Moraxella, including evidence for chromosomal $\beta$ lactamase transfer by conjugation in $B$. catarrhalis, $M$ nonliquefaciens, and $M$. lacunata. Antimicrob Agents Chemother 1989; 33: 1845-1854.

51. Philippon A, Riou JY, Guibourdenche M, Sotolongo F. Detection, distribution and inhibition of Branhamella catarrhalis $\beta$-lactamases. Drugs 1986; 31 Suppl 3: 64-69.

52. Hoi-Dang AB, Brisele Bouguenec C, Barthelemy M, Labia R. Novel $\beta$-lactamase from Branhamella catarrhalis. Ann Microbiol 1978; 129B: 397-406.

53. Wallace RJ, Nash DR, Steingrube VA. Antibiotic susceptibilities and drug resistance in Moraxella (Branhamella) catarrhalis. Am J Med 1990; 88 Suppl 5A: 46S-50S.

54. Fung CP, Powell M, Seymour A, Yuan M, Williams JD. The antimicrobial susceptibility of Moraxella catarrhalis isolated in England and Scotland in 1991. J Antimicrob Chemother 1992; 30: 47-55.

55. Farmer T, Reading C. $\beta$-lactamases of Branhamella catar rhalis and their inhibition by clavulanic acid. Antimicrob Agents Chemother 1982; 21: 506-508.

56. Nash DR, Wallace RJ, Steingrube VA, Shurin PA. Isoelectric focusing of $\beta$-lactamases from sputum and middle ear isolates of Branhamella catarrhalis recovered in the United States. Drugs 1986; 31 Suppl 3: 48-54.

57. Fung C-P, Yeo S-F, Livermore DM. Extraction of betalactamase from Moraxella catarrhalis. $J$ Antimicrob Che mother 1994; 34: 183-184.

58. Kamme C, Vang $M$, Ståhl S. Intrageneric and intergeneric transfer of Branhamella catarrhalis $\beta$-lactamase production. Scand J Infect Dis 1984; 16: 153-155.

59. Kamme $\mathrm{C}$, Vang $\mathrm{M}$, Ståhl $\mathrm{S}$. Transfer of $\beta$-lactamase production in Branhamella catarrhalis. Scand $J$ Infect Dis 1983; 15: 225-226.

60. Eliasson I, Kamme C, Prellner K. Beta-lactamase production in the upper respiratory tract flora. Eur $J$ Clin Microbiol 1986; 5: $507-512$

61. Steingrube VA, Wallace RJ, Beaulieu D. A membrane-bound precursor $\beta$-lactamase in strains of Moraxella catarrhalis and Moraxella nonliquefaciens that produce periplasmic BRO-1 and BRO-2 $\beta$-lactamases. $J$ Antimicrob Chemother 1993; 31 237-244.

62. Kamme C, Eliasson I, Knutson BK, Vang M. Plasmid mediated $\beta$-lactamase in Branhamella catarrhalis. Drugs 1986; 31 Suppl 3: 55-63.

63. Mölstad S, Eliasson I, Hovelius B, Kamme C, Schalén C Beta-lactamase production in the upper respiratory tract flora in relation to antibiotic consumption: a study in children attending day nurseries. Scand J Infect Dis 1988; 20: 329 334.

64. Christensen JJ, Keiding J, Schumacher H, Bruun B. Recognition of a new Branhamella catarrhalis $\beta$-lactamase BRO-3. $J$ Antimicrob Chemother 1991; 28: 774-775.

65. Robledano L, Rivera MJ, Otal I, Gomez-Lus R. Enzymatic modification of aminoglycoside antibiotics by Branhamella catarrhalis carrying an R factor. Drugs Exp Clin Res 1987; 13: $137-143$

66. Hol C, van Dijke EEM, Verduin CM, Verhoef J, van Dijk H Experimental evidence for Moraxella-induced penicillin neutralization in pneumococcal pneumonia. J Infect Dis 1994; 170: $1613-1616$

67. Wardle JK. Branhamella catarrhalis as an indirect pathogen Drugs 1986; 31 Suppl 3: 93-96.

68. Doern GV. Trends in antimicrobial susceptibility of bacterial pathogens of the respiratory tract. Am J Med 1995; 99 Suppl 6B: $3 \mathrm{~S}-7 \mathrm{~S}$.

69. Kallings I. Sensitivity of Branhamella catarrhalis to oral antibiotics. Drugs 1986; 31 Suppl 3: 17-22.

70. Roberts MC, Pang Y, Spencer RC, Winstanley TG, Brown BA, Wallace RJ. Tetracycline resistance in Moraxella (Branhamella) catarrhalis: demonstration of two clonal outbreaks by using pulsed-field gel electrophoresis. Antimicrob Agents Chemother 1991; 35: 2453-2455. 
71. Zheng X, Cao Y. Beta-lactamase producing Branhamella in Beijing, China. Pediatr Infect Dis J 1988; 7: 744.

72. Vaneechoutte $M$, Verschraegen G, Claeys G, van den Abeele A-M. Serological typing of Branhamella catarrhalis strains on the basis of lipopolysaccharide antigens. J Clin Microbiol 1990; 28: 182-187.

73. Ahmad F, McLeod DT, Power JT, Calder MA. Branhamella catarrhalis prevalence in a hospital population. J Hosp Infect 1985; 6: 71-74

74. Bartos LC, Murphy TF. Comparison of the outer membrane proteins of 50 strains of Branhamella catarrhalis. $J$ Infect Dis 1988; 158: 761-765.

75. Picard B, Goullet P, Denamur E, Suermondt G. Esterase electrophoresis: a molecular tool for studying the epidemiology of Branhamella catarrhalis nosocomial infection. Epidemiol Infect 1989; 103: 547-554.

76. Fox RH, McClain DE. Evaluation of the taxonomic relationship of Micrococcus cryophilus, Branhamella catarrhalis, and Neisseriae by comparative polyacrylamide gel electrophoresis of soluble proteins. Int $J$ Syst Bacteriol 1974; 24: 172-176.

77. Soto-Hernandez JL, Holtsclaw-Berk S, Harvill LM, Berk SL. Phenotypic characteristics of Branhamella catarrhalis strains. $J$ Clin Microbiol 1989; 27: 903-908.

78. Cook PP, Hecht DW, Snydman DR. Nosocomial Branhamella catarrhalis in a paediatric intensive care unit: risk factors for disease. J Hosp Infect 1989; 13: 299-307.

79. Kawakami Y, Ueno I, Katsuyama T, Furihata K, Matsumoto H. Restriction fragment length polymorphism (RFLP) of genomic DNA of Moraxella (Branhamella) catarrhalis isolates in a hospital. Microbiol Immunol 1994; 38: 891-895.

80. Tenover FC, Arbeit RD, Goering RV et al. Interpreting chromosomal DNA restriction patterns produced by pulsedfield gel electrophoresis: criteria for bacterial strain typing. $J$ Clin Microbiol 1995; 33: 2233-2239.

81. Selander RK, Caugant DA, Whittam TS. Genetic structure and variation in natural populations of Escherichia coli. In: Neidhardt FC, Ingraham JL, Law KB, Magasanik B, Schaechter M, Umbarger HE (eds) Escherichia coli and Salmonella typhimurium: cellular and molecular biology, vol 2. Washington, USA. American Society for Microbiology. 1987: $1625-1648$.

82. Smith JM, Smith NH, O'Rourke M, Spratt BG. How clonal are bacteria? Proc Natl Acad Sci USA 1993; 90: 4384-4388.

83. Murphy TF. The surface of Branhamella catarrhalis: a systematic approach to the surface antigens of an emerging pathogen. Pediatr Infect Dis $J$ 1989; 81 Suppl: S75-S77.

84. Edebrink P, Jansson P-E, Rahman MM et al. Structural studies of the O-polysaccharide from the lipopolysaccharide of Moraxella (Branhamella) catarrhalis serotype A (strain ATCC 25238). Carbohydr Res 1994; 257: 269-284.

85. Masoud H, Perry MB, Brisson J-R, Uhrin D, Richards JC. Structural elucidation of the backbone oligosaccharide from the lipopolysaccharide of Moraxella catarrhalis serotype A. Can J Chem 1994; 72: 1466-1477.

86. Rahman M, Holme T. Antibody response in rabbits to serotype-specific determinants in lipopolysaccharides from Moraxella catarrhalis. J Med Microbiol 1996; 44: 348-354.

87. Edebrink P, Jansson P-E, Rahman MM, Widmalm G, Holme T, Rahman M. Structural studies of the O-antigen oligosaccharides from two strains of Moraxella catarrhalis serotype C. Carbohydr Res 1995; 266: 237-261.

88. Doyle WJ. Animal models of otitis media: other pathogens. Pediatr Infect Dis J 1989; 81 Suppl: S45-S47.

89. Storm Fomsgaard J, Fomsgaard A, Høiby N, Bruun B, Galanos C. Comparative immunochemistry of lipopolysaccharides from Branhamella catarrhalis strains. Infect Immun 1991; 59: 3346-3349.

90. Beachey EH. Bacterial adherence: adhesin-receptor interactions mediating the attachment of bacteria to mucosal surfaces. J Infect Dis 1981; 143: 325-345.

91. Marrs CF, Weir S. Pili (fimbriae) of Branhamella species. Am $J$ Med 1990; 88 Suppl 5A: 36S-40S.

92. Hermodson MA, Chen KCS, Buchanan TM. Neisseria pili proteins: amino-terminal amino acid sequences and identification of an unusual amino acid. Biochemistry 1978; 17: $442-445$.

93. Schoolnik GK, Fernandez R, Tai YT, Rothbard J, Gothschlich EC. Gonococcal pili: primary structure and receptor binding domain. J Exp Med 1984; 159: 1351-1370.
94. Froholm LO, Sletten K. Purification and N-terminal sequence of a fimbrial protein from Moraxella nonliquefaciens. FEBS Lett 1977; 73: 29-32.

95. Sastry PA, Pearlstone JR, Smillie LB, Paranchych W. Amino acid sequence of pilin isolated from Pseudomonas aeruginosa PAK. FEBS Lett 1983; 151: 253-256.

96. Taylor RK, Miller VL, Furlong DB, Mekalanos JJ. Use of phoA gene fusions to identify a pilus colonization factor coordinately regulated with cholera toxin. Proc Natl Acad Sci USA 1987; 84: 2833-2837.

97. Marrs CF, Schoolnik G, Koomey JM, Hardy J, Rothbard J, Falkow S. Cloning and sequencing of a Moraxella bovis pilin gene. J Bacteriol 1985; 163: 132-139.

98. Ruehl WW, Marrs CF, Fernandez R, Falkow S, Schoolnik GK. Purification, characterization, and pathogenicity of Moraxella bovis pili. J Exp Med 1988; 168: 983-1002.

99. Klemm P. Fimbrial adhesins of Escherichia coli. Rev Infect Dis 1985; 7: 321-340.

100. Ahmed K, Rikitomi N, Nagatake T, Matsumoto K. Electron microscopic observation of Branhamella catarrhalis. Microbiol Immunol 1990; 34: 967-975.

101. Ahmed K, Rikitomi N, Matsumoto K. Fimbriation, hemagglutination and adherence properties of fresh clinical isolates of Branhamella catarrhalis. Microbiol Immunol 1992; 36: 1009-1017.

102. Ahmed K, Masaki H, Dai TC et al. Expression of fimbriae and host response in Branhamella catarrhalis respiratory infections. Microbiol Immunol 1994; 38: 767-771.

103. Ahmed K, Matsumoto K, Rikitomi N, Nagatake T. Attachment of Moraxella catarrhalis to pharyngeal epithelial cells is mediated by a glycosphingolipid receptor. FEMS Microbiol Lett 1996; 135: 305-309.

104. Densen P. Interaction of complement with Neisseria meningitidis and Neisseria gonorrhoeae. Clin Microbiol Rev 1989; 2 Suppl: S11-S17.

105. Densen P. Complement deficiencies and meningococcal disease. Clin Exp Immunol 1991; 86 Suppl 1: 57-62.

106. Verduin CM, Hol C, Bootsma HJ, Verhoef J, van Dijk H. Observations on constitutional resistance to infection. Immunol Today 1993; 14: 44-45.

107. Verduin CM, Jansze M, Hol C, Mollnes TE, Verhoef J, van Dijk H. Differences in complement activation between complement-resistant and complement-sensitive Moraxella (Branhamella) catarrhalis strains occur at the level of membrane attack complex formation. Infect Immun 1994; 62: $589-595$

108. Helminen ME, Maciver I, Paris M et al. A mutation affecting expression of a major outer membrane protein of Moraxella catarrhalis alters serum resistance and survival in vivo. $J$ Infect Dis 1993; 168: 1194-1201.

109. Hol C, Verduin CM, Van Dyke EEA, Verhoef J, Fleer A, van Dijk H. Complement resistance is a virulence factor of Branhamella (Moraxella) catarrhalis. FEMS Immunol Med Microbiol 1995; 11: 207-212.

110. Payne SM. Iron acquisition in microbial pathogenesis. Trends Microbiol 1993; 1: 66-69.

111. Wooldridge KG, Williams PH. Iron uptake mechanisms of pathogenic bacteria. FEMS Microbiol Rev 1993; 12: $325-348$.

112. Cornelissen $\mathrm{CN}$, Sparling $\mathrm{PF}$. Iron piracy: acquisition of transferrin-bound iron by bacterial pathogens. Mol Microbiol 1994; 14: $843-850$

113. Schryvers AB, Lee BC. Comparative analysis of the transferrin and lactoferrin binding proteins in the family Neisseriaceae. Can J Microbiol 1989; 35: 409-415.

114. Campagnari AA, Shanks KL, Dyer DW. Growth of Moraxella catarrhalis with human transferrin and lactoferrin: expression of iron-repressible proteins without siderophore production. Infect Immun 1994; 62: 4909-4914.

115. Novotny P, Short JA, Walker PD. An electron-microscope study of naturally occurring and cultured cells of Neisseria gonorrhoeae. J Med Microbiol 1975; 8: 413-427.

116. Reyn A. Family I. Neisseriaceae Prévot. In: Buchanan RE, Gibbons NE (eds) Bergey's Manual of determinative bacteriology, 8th edn. Baltimore, Williams and Wilkins. 1974: $427-433,442-443$

117. Hellio R, Guibourdenche M, Collatz E, Riou JY. The envelope structure of Branhamella catarrhalis as studied by transmission electron microscopy. Ann Inst Pasteur 
Microbiol 1988; 139: 515-525.

118. Ahmed K, Rikitomi N, Ichinose A, Matsumoto K. Possible presence of a capsule in Branhamella catarrhalis. Microbiol Immunol 1991; 35: 361-366.

119. Devalia JL, Grady D, Harmanyeri Y, Tabaqchali S, Davies RJ. Histamine synthesis by respiratory tract micro-organisms: possible role in pathogenicity. J Clin Pathol 1989; 42: 516-522.

120. Wilson R. Haemophilus influenzae in chronic and recurrent chest infections. Respir Dis Pract 1987; Suppl 1: 7.

121. Eliasson I. Serological identification of Branhamella catarrhalis. Serological evidence for infection. Drugs 1986; 31 Suppl 3: 7-10.

122. Goldblatt D, Turner MW, Levinsky RJ. Branhamella catarrhalis: antigenic determinants and the development of the $\mathrm{IgG}$ subclass response in childhood. J Infect Dis 1990; 162: $1128-1135$.

123. Carson RT, McDonald DF, Kehoe MA, Calvert JE. Influence of $\mathrm{Gm}$ allotype on the IgG subclass response to streptococcal $\mathrm{M}$ protein and outer membrane proteins of Moraxella catarrhalis. Immunology 1994; 83: 107-113.

124. Murphy TF. Studies of the outer membrane proteins of Branhamella catarrhalis. Am J Med 1990; 88 Suppl 5A:
41S-45S.

125. Helminen ME, Maciver I, Latimer JL et al. A large, antigenically conserved protein on the surface of Moraxella catarrhalis is a target for protective antibodies. J Infect Dis 1994; 170: 867-872.

126. Helminen ME, Beach R, Maciver I, Jarosik G, Hansen EJ, Leinonen $M$. Human immune response against outer membrane proteins of Moraxella (Branhamella) catarrhalis determined by immunoblotting and enzyme immunoassay. Clin Diagn Lab Immunol 1995; 2: 35-39.

127. Sethi S, Hill SL, Murphy TF. Serum antibodies to outer membrane proteins (OMPs) of Moraxella (Branhamella) catarrhalis in patients with bronchiectasis: identification of OMP B1 as an important antigen. Infect Immun 1995; 63: $1516-1520$.

128. Sarwar J, Campagnari AA, Kirkham C, Murphy TF. Characterization of an antigenically conserved heat-modifiable major outer membrane protein of Branhamella catarrhalis. Infect Immun 1992; 60: 804-809.

129. Rahman M, Holme T, Jonsson I, Krook A. Lack of serotypespecific antibody response to lipopolysaccharide antigens of Moraxella catarrhalis during lower respiratory tract infection. Eur J Clin Microbiol Infect Dis 1995; 14: 297-304. 